\title{
Effects of ciprofloxacin on turion germination and seedling development in two submerged aquatic plants
}

\section{Pei Fan}

Wuhan University

Chunhua Liu

Wuhan University

Zhen Ke

Wuhan University

Wei Zhou

Wuhan University

Zhonghua Wu ( $\nabla$ wuzhonghua@whu.edu.cn )

Wuhan University https://orcid.org/0000-0003-0810-7470

\section{Research Article}

Keywords: antibiotic, turions, germination, seedling growth, antioxidants

Posted Date: March 23rd, 2022

DOI: https://doi.org/10.21203/rs.3.rs-1273334/v2

License: (c) (i) This work is licensed under a Creative Commons Attribution 4.0 International License. Read Full License 


\section{Abstract}

Germination and seedling development are crucial processes for plant growth and survival, and asexual propagules are predominant reproduction organs for aquatic plants. Ciprofloxacin is widely detected in both terrestrial and aquatic ecosystems, while studies on its effects on germination and seedling development mainly focused on terrestrial plants. We evaluated effects of ciprofloxacin $(0.1,1,5$ and $10 \mathrm{mg} / \mathrm{L})$ on turion germination and early establishment of two submerged plants species (Potamogeton crispus and Hydrilla verticillata). Results showed that germination rate and rooting rate of both species were not impacted by ciprofloxacin. However, $0.1 \mathrm{mg} / \mathrm{L}$ ciprofloxacin significantly accelerated germination of $H$. verticillata and 5$10 \mathrm{mg} / \mathrm{L}$ ciprofloxacin significantly delayed rooting of both species. With rising ciprofloxacin concentrations and prolonging exposure time, seedling tolerance index and root number of both species decreased significantly, and shoot number decreased slightly in P. crispus but kept increasing in H. verticillata, suggesting better tolerance of $H$. verticillata under ciprofloxacin exposure. Root and shoot biomass accumulation, photosynthetic pigments contents of both species were all significantly inhibited. To defense against oxidative stress and prevent lipid peroxidation, antioxidants of both species including superoxide dismutase, catalase, guaiacol peroxidase, polyphenol oxidase, ascorbate peroxidase, ascorbic acid, reduced glutathione were activated to varying degrees. By integrating biomarker responses, we found the stress degree of ciprofloxacin on seedlings of both species was enhanced with increasing ciprofloxacin concentrations. Overall, ciprofloxacin impacted turion germination process and harmed early establishment of both species, suggesting potentially adverse effects of ciprofloxacin pollution on survival and expansion of submerged aquatic plant populations.

\section{Introduction}

Submerged plants, the main primary producers in shallow fresh waters, could provide habitats, shelters and food sources for fishes, aquatic macroinvertebrates and waterbirds, contributing to their important roles in the maintenance of structure and function of shallow-water ecosystems (Yuan et al. 2018; Özgencil et al. 2020). However, in recent years, because of factors such as climate changes (Yan et al. 2021), fishery impacts (Ren et al. 2022) and water pollutions (Wu et al. 2021; Hua et al. 2022; Zhang et al. 2021), submerged vegetations are experiencing serious deterioration (Phillips et al. 2016). For instance, in eutrophic water bodies, toxic microcystins produced by massive cyanobacterial blooms would deteriorate water quality and seriously threaten the growth and survival of submerged plants ( $\mathrm{Ha}$ and Pflugmacher 2013). Additionally, as emerging pollutants, fluoroquinolone antibiotics have become one of the most common categories of harmful pollutants in lakes (Chen et al. 2020), rivers (Pan et al. 2020) and even seawaters (Wu et al. 2022). Polluted waters containing fluoroquinolone antibiotics could impact aquatic community structure and might act as possible causes of the decline and disappearance of aquatic plants (Robinson et al. 2005).

Ciprofloxacin is a fluoroquinolone antibiotic that has been widely used in aquaculture, treatments of human ailments and pharmaceutical industries. Consequently, agricultural wastewater, hospital effluent, domestic sewage and industrial emissions are the main sources of ciprofloxacin pollution in natural water bodies (Adeleye et al. 2022). For example, ciprofloxacin (mean concentration, detected frequency) was detected in 
drinking water (169.2 ng/L, 94.9\%), surface water (28 ng/L, 100\%) and ground water (77.2 ng/L, 45\%) (BoyRoura et al. 2018; Pan et al. 2020; Chen et al. 2018). Enormously high concentrations of ciprofloxacin in effluents of wastewater treatment plants $(14 \mathrm{mg} / \mathrm{L})$ and lakes $(6.5 \mathrm{mg} / \mathrm{L})$ have also been reported by Fick et al (2009). In estuarine water and seawater of Laizhou Bay in northern China, ciprofloxacin was one of the most dominant antibiotics which contributed to over $70 \%$ of the total antibiotic burden (Lu et al. 2022). Moreover, by inducing antibiotic resistance (Yang et al. 2020), ciprofloxacin could cause adverse effects on human health at even low concentrations (ng/L) (Koczura et al. 2012; Marchant 2018). Therefore, ciprofloxacin has been proposed to be prioritized and strictly controlled to reduce its negative effects on food chains and ecological systems (Han et al. 2020).

Generally, environmental stresses could impact vegetative growth and physiological stability of aquatic plants (Bornette and Puijalon 2010; Yu et al. 2022). For example, ciprofloxacin (0.01-1mg/L) significantly decreased the photosynthetic pigment contents, disrupted PSII integrity, affected leave growth and triggered reactive oxygen species (ROS) accumulations and oxidative stress in a floating plant Eichhornia crassipes (Yan et al. 2019). Root developments, chlorophyll contents, superoxide dismutase (SOD) and guaiacol peroxidase (POD) activities and root activity of the emergent plant species Phragmites australis were all evidently inhibited by a mixture of ciprofloxacin, oxytetracycline and sulfamethazine (Liu et al. 2013). As for submerged plants, Ebert et al (2011) found the 7-day NOEC (the no-observed-effect concentration) of ciprofloxacin based on root elongation of Myriophyllum spicatum $\mathrm{L}$ was higher than $0.98 \mathrm{mg} / \mathrm{L}$. These studies mainly focused on vegetative growth stage. However, researches on other life history stages such as germination and reproduction are limited. As an example, it has been reported that ciprofloxacin at 0.2-2 $\mathrm{mg} / \mathrm{L}$ did not affect the germination rate of maize seeds but significantly reduced the germination time (Gomes et al. 2019). But no investigations on the effects of ciprofloxacin on germination phase of aquatic species have been reported.

Vegetative propagation is one of the main modes of reproduction for submerged plants, and turions of submerged plants are modified vegetative organs produced via asexual processes (Adamec 2018). With functional similarity to seeds, turions also have the ability to generate progeny plants (Song et al. 2017). What is more, due to their tolerance to extreme conditions such as coldness, darkness and hypoxiation of the underwater environments, turions play key roles in maintaining submerged plant community (Adamec 2008). Nowadays, in China, sowing turions of submerged plants have become one of the most common practices for restoration of damaged submerged vegetation in lakes and ponds (Jian et al. 2003; Song et al. 2017). Undoubtedly, germination of turions and early establishment are crucial stages that could directly influence the biomass accumulations and population expansion of submerged plants. Hydrilla verticillata is a dominant submerged species in many freshwater lakes, while Potamogetom crispus could be widely found in shallow lakes, ponds, rice paddies and rivers (Jian et al. 2003; Li et al. 2021). Additionally, due to their good performances in purifying water, these two submerged plants have been widely used as pioneer species in restoration of submerged plants for governing eutrophication (Li et al. 2021; Wang et al. 2017). However, ecotoxicological effects of ciprofloxacin on turion germination and seedling development of these two submerged plants have not been reported. 
Biomarkers, or biochemical endpoints, are often used to clarify the mechanism of action of chemicals. Moreover, there usually more than one biomarker response is assessed in organisms exposed to toxic chemicals or stressed conditions. Thus, integrating multiple biomarkers is a valid and reliable approach to characterize a holistic degree of stress suffered by aquatic plants (Bertrand et al. 2019). Endpoints during germination and root development are simple but sensitive, which are generally employed for assessment of phytotoxicity of chemicals to plants (Liu et al. 2017). Thus, effective concentrations that are obtained from quantitative structure-activity relationship model are widely used for ecological risk assessment of pollutants (Pan and Chu 2016). Therefore, in the present study, we investigate effects of ciprofloxacin on turions germination, root elongation, seedling development, and biomass accumulation, photosynthetic pigment contents, $\mathrm{H}_{2} \mathrm{O}_{2}$ content, lipid peroxidation degree, seven antioxidants of $P$. crispus and $H$. verticillata. The relationships between seedling tolerance and drug concentrations were established and inhibitory concentrations were obtained for evaluation of ciprofloxacin phytotoxicity to plants. Furthermore, physiological endpoints were integrated to reflect the holistic levels of stress on plants. Our aims were to (1) evaluate the sensitivity of different endpoints during germination and seedling phases to ciprofloxacin, (2) try to compare the tolerance of $P$. crispus and $H$. verticillata seedlings to ciprofloxacin, (3) to explore toxicity threshold of ciprofloxacin based on seedling tolerance, $(4)$ to explore the stress levels of ciprofloxacin on both plants and reveal the physiological mechanism that was involved in plant adaptation to ciprofloxacin. This study might help to evaluate the ecotoxicity of ciprofloxacin to submerged species, predict their population dynamics under ciprofloxacin pollution and provide theoretical guidance for restoration of degraded shallow waters polluted by ciprofloxacin.

\section{Materials And Methods}

\subsection{Plant materials and experimental design}

P. crispus turions (green turions, weighing $0.68 \pm 0.12 \mathrm{~g}, \mathrm{n}=250$ ) were hand collected in September 2020 from Lake Diaocha $\left(30^{\circ} 69^{\prime} \mathrm{N} ; 113^{\circ} 72^{\prime} \mathrm{E}\right)$ in Hubei Province, PR China. After cleaning thoroughly, the turions were transported into a climate chamber on 20 September. Turions of $H$. verticillata (weighing $0.15 \pm 0.01 \mathrm{~g}$, $\mathrm{n}=250$ ) were hand collected in January 2021 from Lake Diaocha. After cleaning thoroughly, the turions were transported into a climate chamber on 5 January.

During the whole experiment, the turions/seedlings of $P$. crispus or $\mathrm{H}$. verticillata were cultivated in $10 \%$ Hoagland's solution in a transparent container (Hoagland and Arnon 1950) at $15 \pm 2^{\circ} \mathrm{C}$ or $25 \pm 2^{\circ} \mathrm{C}$ with a $12 / 12$ light/dark cycle and a photon flux density of $30-40 \mu \mathrm{mol}$ photons $\mathrm{m}^{-2} \mathrm{~s}^{-1}$. The turions/seedlings were exposed to various concentrations of ciprofloxacin $(0,0.1,1,5$ and $10 \mathrm{mg} / \mathrm{L})$ and turions (seedlings) and nutrient solution without ciprofloxacin was set as the control group. The whole observation lasted for 35 days (d), where turions were kept in a solution volume of $2 L$ during germination ( $0-7 d$ ), and seedlings (8$35 d)$ were kept in $5 \mathrm{~L}$ solution to meet enough space for their growth. Germination experiment was performed in five replicates with each replicate containing 10 uniform turions. At $8 d$, uniform seedlings from different treatments were respectively selected for further investigation, where each treatment had five replicates and each replicate contained five seedlings. To maintain approximately constant concentrations of ciprofloxacin and nutrients, they were changed every 48 hours during the whole observation. Germination 
parameters were investigated in the first $7 d$, and rooting parameters were investigated at 6-14d. Seedling growth and tolerance indicators of seedlings were investigated at 7, 14, 21, 28 and $35 \mathrm{~d}$ respectively. Plant biomass and physiological responses of seedlings were analyzed at $35 \mathrm{~d}$.

Ciprofloxacin used in the experiments was ciprofloxacin monohydrochloride monohydrate (Purity $\geq 98 \%$; CAS N0. 86393-32-0), and was purchased from Aladdin Reagent Co., Ltd. (Shanghai, China).

\section{2 Ciprofloxacin concentrations analysis}

The actual concentrations of ciprofloxacin were determined $1 \mathrm{~h}$ after being added into the experimental containers, which were $0.1135 \pm 0.0022,1.0483 \pm 0.0047,4.5034 \pm 0.0484$ and $9.7506 \pm 0.0868 \mathrm{mg} / \mathrm{L}(\mathrm{n}=3)$ for the nominal concentrations of $0.1,1,5$ and $10 \mathrm{mg} / \mathrm{L}$, respectively. Ciprofloxacin concentrations were analyzed by high performance liquid chromatography (HPLC, Agilent1100, USA). The mobile phase was $0.025 \mathrm{~mol} / \mathrm{L}$ phosphoric acid $(\mathrm{pH}=2.5$, regulated by triethylamine) and acetonitrile, where the volume ratio of phosphoric acid and acetonitrile was 83:17, using C18 column (Agilent, 20RBAX SB-C18, $4.6 \mathrm{~mm} \times 250$ $\mathrm{mm}, 5 \mu \mathrm{m}$ particle size), with a flow rate of $1.0 \mathrm{ml} / \mathrm{min}$ and excitation/emission wavelength at 278/453 $\mathrm{nm}$. The limit of detection was $0.1 \mu \mathrm{g} / \mathrm{L}$. External standards were used for quantitative determination. The calibration curves showed good linearity for the analyte, with correlation coefficients of 0.9994 .

\section{3 Estimation of germination and rooting}

P. crispus turions were considered germinated when $5 \mathrm{~mm}$ of shoot had emerged, and the turions of $H$. verticillata were considered germinated once evident elongation $(\geq 1 \mathrm{~cm})$ of the buds (internodes) had emerged. Germination rate (percentage) and germination time were documented in the first $7 \mathrm{~d}$. For both species, rooting rate (percentage) and rooting time were recorded when $5 \mathrm{~mm}$ of radicle (root) had emerged. Both germination rate and rooting rate were displayed as $x$ percentage $(\%)$ of the control. Germination time and rooting time were calculated according to Ellis and Roberts (1981):

Germination time (days) $=\frac{\sum D n}{\sum n}$,

rooting time (days) $=\frac{\sum D n}{\sum n}$.

Where $D$ was the number of days since the beginning of the experiment, $n$ was the number of germinated/rooted turions on day D.

\section{4 Seedling growth, tolerance indicators and IC50 assessment}

Shoot number and root number were used to assess growth status of both $P$. crispus and $H$. verticillata seedlings under ciprofloxacin treatment. Due to the structural differences between these two species, the shoot of $\mathrm{H}$. verticillata referred to the stolon branch in this study. Root tolerance index (RTI) and shoot tolerance index (STI) were used to assess seedling tolerance to ciprofloxacin exposure. RTI and STI were calculated according to Rossato et al (2011):

RTI $(\%)=\frac{\text { Lengthofthelongestrootinciprofloxacintreatment }}{\text { Lengthofthelongestrootinthecontrol }} \times 100$, 
STI $(\%)=\frac{\text { Lengthofthelongestshootinciprofloxacintreatment }}{\text { Lengthofthelongestshootinthecontrol }} \times 100$.

Inhibition rate (IR, \%) based on RTI and STI was calculated according to the following equation:

$\mathrm{IR}=\left(\mu_{0}-\mu_{\mathrm{t}}\right) / \mu_{0} \times 100$,

Where $\mu_{0}$ was the value of the control and $\mu_{t}$ was the corresponding value of treatment groups at the same sampling date. To acquire ciprofloxacin effect on seedling tolerance as time elapsed, regression models between the IR values and ciprofloxacin concentrations were eatablished at 7, 14, 21, 28 and 35d using liner regression techniques performed in $\mathrm{R}$ software (version 4. 0. 4), and the inhibitory concentrations (IC50, inhibitory concentration causing $50 \%$ of an endpoint) with a $95 \%$ confidence interval $(95 \% \mathrm{Cl})$ were calculated. Regression models and details were shown in supplementary information.

\section{5 Plant biomass}

At 35d, after blotting water with filter paper, the shoot biomass and root biomass of both $P$. crispus and $H$. verticillata seedlings were estimated by an electronic analytical balance (accuracy $0.1 \mathrm{mg}$ ), where the biomasses were fresh weights (FW).

\section{6 Photosynthetic pigment measurement}

The contents ( $\mathrm{mg} / \mathrm{g} \mathrm{FW}$ ) of photosynthetic pigment were determined based on the method of Jampeetong and Brix (2009) with some modifications. Fresh plant leaves $(0.1 \mathrm{~g}, \mathrm{FW})$ were cut into pieces and placed in 5$\mathrm{ml}$ flasks. Then, $5 \mathrm{ml} \mathrm{95 \%} \mathrm{ethanol} \mathrm{was} \mathrm{added} \mathrm{into} \mathrm{the} \mathrm{flasks} \mathrm{to} \mathrm{extract} \mathrm{the} \mathrm{photosynthetic} \mathrm{pigment} \mathrm{in} \mathrm{the}$ dark for $24 \mathrm{~h}$. Plant pigment contents were determined with a spectrophotometer at 470, 649 and $645 \mathrm{~nm}$ for chlorophyll a, chlorophyll b and carotenoids, respectively. Values were calculated according to Lichtenthaler and Wellburn (1983). All spectrophotometric analyses involved in this experiment were accomplished with a MAPADA UV-1200 spectrophotometer (Shanghai Meipuda Instrument Co. Ltd., Shanghai, China).

\section{7 Lipid perioxidation measurement}

Malondialdehyde (MDA) content ( $\mu \mathrm{mol} / \mathrm{g} \mathrm{FW}$ ) was used as a proxy of lipid peroxidation level. Plant leaves $(0.1 \mathrm{~g}, \mathrm{FW})$ were homogenized using $3 \mathrm{ml} \mathrm{10 \%} \mathrm{(w/v)} \mathrm{trichloroacetic} \mathrm{acid} \mathrm{(TCA),} \mathrm{and} \mathrm{then} \mathrm{the} \mathrm{homogenate}$ was centrifugated at $4000 \mathrm{rpm}$ for $10 \mathrm{~min}$ at $4^{\circ} \mathrm{C}$. For every $1 \mathrm{~mL}$ of supernatant, $1 \mathrm{~mL} 0.6 \%(\mathrm{w} / \mathrm{v})$ thiobarbituric acid (TBA) was added. The reaction mixture was heated at $95^{\circ} \mathrm{C}$ for $25 \mathrm{~min}$ and centrifugated at $4000 \mathrm{rpm}$ for $10 \mathrm{~min}$ at $4^{\circ} \mathrm{C}$ after being cooled quickly. The resulting supernatant was analyzed at 450 , 532 and $600 \mathrm{~nm}$, respectively (Cang and Zhao 2013).

\section{8 Measurements of enzyme activity, soluble protein and $\mathrm{H}_{2} \mathrm{O}_{2}$ content}

Plant leaves $(0.1 \mathrm{~g}, \mathrm{FW})$ were homogenized using $50 \mathrm{mM}$ phosphate buffer solution $(\mathrm{pH} \mathrm{7.8)}$ containing $1 \%$ $(\mathrm{w} / \mathrm{v})$ polyvinyl pyrrolidone (PVPP) and $0.1 \mathrm{mM}$ ethylenediaminetetraacetic acid (EDTA) at $4^{\circ} \mathrm{C}$. Then, the homogenate was centrifuged at $8000 \times \mathrm{g}$ for $15 \mathrm{~min}$ at $4^{\circ} \mathrm{C}$. The resulting supernatant was used for 
superoxide dismutase (SOD), catalase (CAT), guaiacol peroxidase (POD), polyphenol oxidase (PPO) and ascorbate peroxidase (APX) activity, soluble protein and hydrogen peroxide $\left(\mathrm{H}_{2} \mathrm{O}_{2}\right)$ content assays.

SOD activity was measured at $560 \mathrm{~nm}$ according to Cang and Zhao (2013). The reaction mixture was 50 $\mathrm{mM}$ phosphate buffer solution ( $\mathrm{pH} 7.8$ ) containing $13 \mathrm{mM}$ methionine, 0,075 mM NBT (nitro blue tetrazolium), $0.1 \mathrm{mM}$ EDTA (ethylene diamine tetraacetic acid), $0.002 \mathrm{mM}$ riboflavin and enzyme extract. The unit $(\mathrm{U})$ of SOD activity (U/mg protein) was defined as the amount that resulted in a $50 \%$ inhibition of the initial rate of the reaction in the absence of the enzyme.

CAT activity was determined spectrophotometrically at $240 \mathrm{~nm}$ based on the method of Cang and Zhao (2013). The reaction mixture contained $200 \mathrm{mM}$ phosphate buffer solution (pH 7.8), $100 \mathrm{mM} \mathrm{H}_{2} \mathrm{O}_{2}$ and enzyme extract. The unit of CAT activity $(\mathrm{U} / \mathrm{min} \cdot \mathrm{mg}$ protein) was defined as a decrease of $0.1 \mathrm{in}$ absorbance at $240 \mathrm{~nm}$ in $1 \mathrm{~min}$.

POD activity was measured based on the guaiacol method (Zhang et al. 2009), and the reaction mixture comprised $100 \mathrm{mM}$ potassium phosphate buffer, $20 \mathrm{mM}$ guaiacol, $65 \mathrm{mM} \mathrm{H}_{2} \mathrm{O}_{2}$ and enzyme extract. One unit of POD activity (U/min $\cdot \mathrm{mg}$ protein) was defined as an absorbance change of 0.01 at $470 \mathrm{~nm}$ in $1 \mathrm{~min}$.

PPO activity was determined according to Shi (2016), the reaction mixture was $50 \mathrm{mM}$ phosphate buffer solution ( $\mathrm{pH}$ 6.4) containing $100 \mu \mathrm{M}$ catechol and enzyme extract, with a per-minute absorbance change of 0.01 at $398 \mathrm{~nm}$ as one unit of PPO activity (U/min $\cdot \mathrm{mg}$ protein).

APX activity was measured using the method of Chen et al. (2017), and the reaction solution was $50 \mathrm{mM}$ phosphate buffer ( $\mathrm{pH}$ 7.8) containing $2 \mathrm{mM}$ EDTA, $5 \mathrm{mM}$ AsA (ascorbic acid), $20 \mathrm{mM} \mathrm{H}_{2} \mathrm{O}_{2}$ and enzyme extract. One unit of APX activity ( $\mathrm{U} / \mathrm{min} \cdot \mathrm{mg}$ protein) corresponded to a per-minute absorbance change of 0.01 at $290 \mathrm{~nm}$.

$\mathrm{H}_{2} \mathrm{O}_{2}$ content ( $\mu \mathrm{mol} / \mathrm{g} \mathrm{FW}$ ) was determined according to Shi (2016). Briefly, for every $1 \mathrm{~mL}$ enzyme extract, 1 $\mathrm{mL} 5 \%(\mathrm{w} / \mathrm{v})$ titanium sulfate was added. After $10 \mathrm{~min}$, the reaction solution was centrifuged at $12000 \mathrm{rpm}$ for $10 \mathrm{~min}$ at $4^{\circ} \mathrm{C}$ and the supernatant was then analyzed at $410 \mathrm{~nm}$.

Soluble protein content was determined according to Bradford (1976) and the bovine serum albumin was used as standard. Briefly, the rection mixture contained $5 \mathrm{~mL}$ Coomassie brilliant blue G-250 solution and $0.1 \mathrm{~mL}$ crude extract. After $2 \mathrm{~min}$ of reaction, the soluble protein content (mg/g FW) was calculated by recording the absorbance at $595 \mathrm{~nm}$.

\section{9 Measurement of non-enzymatic antioxidants}

Reduced ascorbic acid (AsA) was determined according to Cang and Zhao (2013) with some modifications. Plant leaves $(0.1 \mathrm{~g}, \mathrm{FW})$ were ground by $4 \mathrm{~mL} 5 \%(\mathrm{w} / \mathrm{v})$ TCA and then centrifuged at $4000 \mathrm{rpm}$ for $10 \mathrm{~min}$ at $4^{\circ} \mathrm{C}$. Then $1 \mathrm{~mL}$ supernatant was mixed with $1 \mathrm{~mL} 5 \%(\mathrm{w} / \mathrm{v})$ TCA, $1 \mathrm{~mL}$ absolute ethanol, $0.5 \mathrm{~mL} 0.4 \%(\mathrm{w} / \mathrm{v})$ $\mathrm{H}_{3} \mathrm{PO}_{4}$ in absolute ethanol, $1 \mathrm{~mL} 0.5 \%(\mathrm{w} / \mathrm{v})$ red phenanthroline (BP) in absolute ethanol and $0.5 \mathrm{~mL} 0.03 \%$ 
$(\mathrm{w} / \mathrm{v}) \mathrm{FeCl}_{3}$. The reaction mixture was then incubated at $30^{\circ} \mathrm{C}$ for $40 \mathrm{~min}$, and the absorbance at $534 \mathrm{~nm}$ was recorded. And a standard curve with AsA was used.

Reduced glutathione (GSH) was determined according to Cang and Zhao (2013) with some modifications. Plant leaves $(0.1 \mathrm{~g}, \mathrm{FW})$ were ground by $3 \mathrm{~mL} 5 \%(\mathrm{w} / \mathrm{v})$ TCA and then centrifuged at $12000 \mathrm{rpm}$ for $20 \mathrm{~min}$ at $4^{\circ} \mathrm{C}$. The reaction mixture contained $1 \mathrm{~mL}$ supernatant, $1 \mathrm{~mL} 100 \mathrm{mM}$ phosphate buffer $(\mathrm{pH} 7.7)$ and 0.5 $\mathrm{mL} 4 \mathrm{mM}$ DTNB (5,5'-dithio (2,2'-dinitro) benzoate) in $100 \mathrm{mM}$ phosphate buffer (pH 6.8). After being incubated at $25^{\circ} \mathrm{C}$ for $10 \mathrm{~min}$, the absorbance of the reaction mixture was recorded at $412 \mathrm{~nm}$.

\section{10 Integrated biomarker response}

To visualize and compare the stress degree among different treatment groups, the integrated biomarker response (IBR) including MDA, $\mathrm{H}_{2} \mathrm{O}_{2}$, SOD, CAT, POD, PPO, APX, AsA and GSH were computed according to Kim et al. (2010). The detailed analysis process was shown in supplementary information. Spearman correlation coefficients were calculated between the IBR levels in both species and ciprofloxacin concentrations.

\section{11 Statistical analyses}

All values were expressed as the mean \pm standard deviation (SD). The Levene and Kolmogorov-Smirnov tests were used to verify homoscedasticity and normality criteria, respectively. One-way analysis of variance (ANOVA) was used for the statistical analysis. And a least significant difference (LSD) test was used to separate differences between pairs of treatments, where all the differences were considered significant at $p$ $<0.05$ (SPSS 23.0, IBM Inc., Chicago, IL, USA). Graphs were produced using Sigma-Plot 12.5 (Systat Software, Inc., USA). No shoots and roots of $H$. verticillata formed at $7 \mathrm{~d}$ and thus no relevant analysis was performed then.

\section{Results}

\section{1 Germination and rooting}

Germination rates of both $P$. crispus and $H$. verticillata were not affected by ciprofloxacin exposure $(p>0.05$; Fig. 1A). Rooting rate of $P$. crispus decreased slightly but not significantly with rising ciprofloxacin concentrations ( $p>0.05$; Fig. 1B) while it showed no significant changes in $H$. verticillata $(p>0.05$; Fig. 1B)

Ciprofloxacin did not affect the germination time of $P$. crispus ( $p>0.05$; Fig.1C), while $0.1 \mathrm{mg} / \mathrm{L}$ treatment significantly decreased the germination time of $H$. verticillata ( $p<0.05$; Fig. $1 \mathrm{C}) .10 \mathrm{mg} / \mathrm{L}$ ciprofloxacin significantly increased the rooting time of $P$. crispus (by $42.5 \%)$ when compared with the control $(p<0.05$; Fig.1D). Rooting time of $H$. verticillata also showed slight increases with increasing ciprofloxacin concentrations, reaching levels significantly higher than the control in $5 \mathrm{mg} / \mathrm{L}$ treatment $(p<0.05$; Fig.1D).

\section{2 Tolerance indicators and seedling growth}


When compared with the control, ciprofloxacin at $1-10 \mathrm{mg} / \mathrm{L}$ and $0.1-10 \mathrm{mg} / \mathrm{L}$ significantly decreased RTI of $P$. crispus at 7-21d and 28-35d, respectively ( $p<0.05$; Fig.2A). Moreover, RTI of $P$. crispus treated with 1-5 $\mathrm{mg} / \mathrm{L}$ decreased significantly over time. $H$. verticillata treated with ciprofloxacin concentrations of 1-10 $\mathrm{mg} / \mathrm{L}$ and $0.1-10 \mathrm{mg} / \mathrm{L}$ showed significantly lower RTI compared to the controls at $14 \mathrm{~d}$ and $21-35 \mathrm{~d}$, respectively ( $p<0.05$; Fig.2B). Regardless of ciprofloxacin concentrations, RTI of $H$. verticillata decreased significantly over time $(p<0.05)$.

The STI of $P$. crispus was not affected by ciprofloxacin at $7 \mathrm{~d}(p>0.05$; Fig. $2 \mathrm{C})$, but decreased significantly at ciprofloxacin concentrations of $5-10 \mathrm{mg} / \mathrm{L}$ and $1-10 \mathrm{mg} / \mathrm{L}$ after $14 \mathrm{~d}$ and $21-35 \mathrm{~d}$, respectively $(p<0.05)$. At $14 d$, ciprofloxacin at all concentrations slightly increased the STI of $H$. verticillata $(p>0.05$; Fig. 2D). At $21 \mathrm{~d}$, the STI of $H$. verticillata increased significantly at $0.1 \mathrm{mg} / \mathrm{L}$ ciprofloxacin but decreased significantly at $10 \mathrm{mg} / \mathrm{L}(p<0.05)$. At 28 and $35 \mathrm{~d}$, it was significantly lowered by ciprofloxacin at $0.1-10 \mathrm{mg} / \mathrm{L}$ and $1-10$ $\mathrm{mg} / \mathrm{L}$, respectively $(p<0.05)$. Additionally, STI of both $P$. crispus and $H$. verticillata treated with $1-5 \mathrm{mg} / \mathrm{L}$ ciprofloxacin decreased significantly over time $(p<0.05)$.

When compared to the controls, root number of $P$. crispus showed no significance at 7-14d but significant decreases in $1-10 \mathrm{mg} / \mathrm{L}$ treatments at $21-35 \mathrm{~d}(p<0.05$, Fig. 2E). Additionally, root number of $P$. crispus under $1 \mathrm{mg} / \mathrm{L}$ ciprofloxacin showed significant increases over time $(p<0.05)$, while plants treated with 5 and $10 \mathrm{mg} / \mathrm{L}$ showed no changes ( $p>0.05$ ) from $21 \mathrm{~d}$ to $35 \mathrm{~d}$, and from $7 \mathrm{~d}$ to $35 \mathrm{~d}$, respectively. At $14-21 \mathrm{~d}$ and $28-$ $35 \mathrm{~d}$, root number of $H$. verticillata decreased significantly with ciprofloxacin concentrations of $1-10 \mathrm{mg} / \mathrm{L}$ and $0.1-10 \mathrm{mg} / \mathrm{L}$, respectively $(p<0.05 ;$ Fig. $2 \mathrm{~F}$ ). Under $0.1 \mathrm{mg} / \mathrm{L}$ ciprofloxacin, root number of $H$. verticillata increased significantly over time $(p<0.05)$, without such increases observed at higher ciprofloxacin concentrations during 21-35d $(p>0.05)$. These results indicated inhibition effect of ciprofloxacin at higher concentrations on the root development of both $P$. crispus and $H$. verticillata seedlings especially at later stages of exposure.

Regardless of time points, shoot number of $P$. crispus decreased slightly with rising ciprofloxacin concentrations while $H$. verticillata showed no alterations compared with their corresponding controls ( $p$ > 0.05 ; Fig. $2 \mathrm{G}-\mathrm{H})$. Additionally, with time prolonging, shoot number of $P$. crispus did not change significantly $(p>0.05)$, while it increased significantly in $H$. verticillata regardless of ciprofloxacin concentrations $(p<$ $0.05)$.

\section{3 Time-dependent IC50 based on STI and RTI}

IC50 values of ciprofloxacin based on RTI and STI of both species decreased over time (Table 1), indicating tolerance of these two plant species was attenuated with prolonged exposure of ciprofloxacin. What's more, regardless of time and species, IC50 values based on RTI were respectively lower than those based on STI, suggesting RTI was more sensitive to ciprofloxacin exposure. 
Table 1

Time-dependent IC50 values of ciprofloxacin based RTI and STI (mg/L, 95\% Cl).

\begin{tabular}{|lllll|}
\hline $\begin{array}{l}\text { Time } \\
\text { (day) }\end{array}$ & P. crispus & \multicolumn{3}{c|}{ H. verticillata } \\
\cline { 2 - 3 } & RTI & STI & RTI & STI \\
\hline
\end{tabular}

\begin{tabular}{|c|c|c|c|c|}
\hline 7 & $\begin{array}{l}3.405(2.458 \\
4.352)\end{array}$ & $N A^{a}$ & NA & NA \\
\hline 14 & $\begin{array}{l}3.308(2.260 \\
4.356)\end{array}$ & $\begin{array}{l}5.566(4.143, \\
6.989)\end{array}$ & $\begin{array}{l}5.896(4.388 \\
7.404)\end{array}$ & NA \\
\hline 21 & $\begin{array}{l}3.133(2.392 \\
3.874)\end{array}$ & $\begin{array}{l}4.487(3.661, \\
5.313)\end{array}$ & $\begin{array}{l}3.492(2.811, \\
5.074)\end{array}$ & $\begin{array}{l}\text { 10.227 (6.661, } \\
13.792)\end{array}$ \\
\hline 28 & $\begin{array}{l}2.302(1.246 \\
3.357)\end{array}$ & $\begin{array}{l}3.876(3.016, \\
4.735)\end{array}$ & $\begin{array}{l}2.939 \text { (1.970, } \\
3.908)\end{array}$ & $6.367(4.930,7.803)$ \\
\hline 35 & $\begin{array}{l}2.203(1.139 \\
3.267)\end{array}$ & $\begin{array}{l}3.453(2.582 \\
4.324)\end{array}$ & $\begin{array}{l}2.635(1.336 \\
3.934)\end{array}$ & $5.636(4.405,6.867)$ \\
\hline
\end{tabular}

NA ${ }^{a}$ referred to "not available" due to lack of significance of the models (no calculation of the IC50 values), or because no radicle or shoot emerged then.

\section{4 Plant biomass}

As shown in Fig.3A, B, ciprofloxacin at $1-10 \mathrm{mg} / \mathrm{L}$ significantly decreased both the shoot biomass and root biomass of $P$. crispus $(p<0.05)$. Significant decreases of the biomasses in $H$. verticillata were observed at ciprofloxacin concentrations of $0.1-10 \mathrm{mg} / \mathrm{L}(p<0.05)$.

\section{5 Photosynthetic pigment contents}

For $P$. crispus, when compared with the corresponding controls, ciprofloxacin at concentrations of $0.1-10$ $\mathrm{mg} / \mathrm{L}, 0.1-10 \mathrm{mg} / \mathrm{L}$ and $5-10 \mathrm{mg} / \mathrm{L}$ significantly decreased the contents of chlorophyll a (by $16.53 \%-92.71 \%$ ), chlorophyll b (by $19.71 \%-92.84 \%$ ) and carotenoid (by $71.24 \%-78.29 \%$ ), respectively ( $p<0.05$; Fig.4A). Contents of chlorophyll a, chlorophyll b and carotenoid of $\mathrm{H}$. verticillata decreased significantly by $58.97 \%-88.54 \%, 51.63 \%-83.91 \%$ and $71.24 \%-78.29 \%$ with ciprofloxacin concentrations of $1-10 \mathrm{mg} / \mathrm{L}$ when compared with their controls ( $p<0.05$; Fig.4B).

\section{6 Physiological responses}

Ciprofloxacin had no significant effects on MDA content of both P. crispus and H. verticillata (Fig. 5, 6A; $p>$ 0.05). $\mathrm{H}_{2} \mathrm{O}_{2}$ content of $P$. crispus and $H$. verticillata was significantly elevated (by $16.02 \%-27.08 \%$ and $29.82 \%-42.06 \%$, respectively) by ciprofloxacin concentrations of $1-10 \mathrm{mg} / \mathrm{L}$ compared to the controls (Fig. $5,6 \mathrm{~B} ; p<0.05)$. 
As shown in Fig.5C, ciprofloxacin sharply elevated SOD activity of $P$. crispus $(p<0.05)$, reaching levels 1.6-5.0 times higher than the control. However, SOD activity of $H$. verticillata showed no significant differences when compared with the control (Fig.6C; $p>0.05$ ). CAT activity of $P$. crispus was significantly inhibited, which declined by up to $22.9 \%, 40.4 \%$ and $59.1 \%$ at 1,5 and $10 \mathrm{mg} / \mathrm{L}$ ciprofloxacin compared with the control, respectively (Fig.5D; $p<0.05$ ). Similarly, CAT activity of $H$. verticillata was declined by up to $17.2 \%, 45.1 \%$ and $36.6 \%$ at 1,5 and $10 \mathrm{mg} / \mathrm{L}$ ciprofloxacin compared with the control, respectively (Fig.6D; $p<0.05$ ). No significance was found in POD activity of $P$. crispus at lower concentrations of ciprofloxacin (0.1-1.0 mg/L; $p>0.05$ ), while it was 17.8-26.1 times higher than the control at 5-10 mg/L ciprofloxacin (Fig.5E; $p<0.05$ ). POD activity of $H$. verticillata showed no changes in $0.1 \mathrm{mg}$ treatment but was increased by up to $66.7 \%-87.6 \%$ in $1-10 \mathrm{mg} / \mathrm{L}$ treatments in relative to the control (Fig.6E; $p<0.05$ ). PPO activity of $P$. crispus was significantly inhibited by ciprofloxacin (Fig.5F; $p<0.05$ ), representing decreases of $40.3 \%-52.3 \%$ compared to the control. However, PPO activity of $H$. verticillata was significantly induced by ciprofloxacin (Fig.6F; $p<0.05$ ), representing increases of $28.4 \%-53.1 \%$ compared to the control. APX activity of $P$. crispus was significantly induced by ciprofloxacin concentrations of $1-5 \mathrm{mg} / \mathrm{L}$ (Fig.5G; $p<0.05$ ), without any significant differences in other treatments. In H. verticillata, APX activity represented an increase of $101.7 \%$ at $10 \mathrm{mg} / \mathrm{L}$ ciprofloxacin compared to the control (Fig.6G; $p<0.05$ ), without significant increases at lower ciprofloxacin concentrations.

AsA content of $P$. crispus was significantly elevated by ciprofloxacin, reaching levels $0.3-4.9$ times higher than the control $(\mathrm{Fig} .5 \mathrm{H} ; p<0.05)$. AsA content of $\mathrm{H}$. verticillata displayed an increasing tendency with increasing ciprofloxacin concentrations, reaching levels 1.3, 2.0 and 3.4 times higher than the control at 1, 5 and $10 \mathrm{mg} / \mathrm{L}$ ciprofloxacin, respectively (Fig. $6 \mathrm{H} ; p<0.05$ ). When compared to the control, no difference was found in GSH content of $P$. crispus at lower ciprofloxacin concentrations $(0.1-1.0 \mathrm{mg} / \mathrm{L} ; p>0.05)$, while it was increased by up to $96.4 \%-414.6 \%$ at $5-10 \mathrm{mg} / \mathrm{L}$ ciprofloxacin (Fig.5l; $p<0.05$ ). Similarly, GSH content of $H$. verticillata showed no significant changes at ciprofloxacin concentrations of $0.1-5 \mathrm{mg} / \mathrm{L}$ (Fig.6l; $p>0.05$ ), while it was elevated by $94.2 \%$ at the highest ciprofloxacin concentration $(p<0.05)$.

\section{7 Integration of biomarker responses}

The scores and IBR values were computed and displayed in Table 2. With rising ciprofloxacin concentrations, the IBR values of both species tended to increase. Additionally, the IBR values of both $P$. crispus and $H$. verticillata showed good positive correlations with ciprofloxacin concentrations $(r=0.991, p<$ $0.05 ; r=0.943, p<0.05$, respectively), indicating that higher concentrations of ciprofloxacin caused higher degree of stress on these two species. 
Table 2

The scores of biomarkers and integrated biomarker response (IBR) values in P. crispus and $H$. verticillata exposed to different ciprofloxacin concentrations.

\begin{tabular}{|c|c|c|c|c|c|c|c|c|c|c|}
\hline \multirow[t]{2}{*}{ Biomarkers } & \multicolumn{5}{|c|}{ P. crispus } & \multicolumn{5}{|c|}{ H. verticillata } \\
\hline & Control & $\begin{array}{l}0.1 \\
\mathrm{mg} / \mathrm{L}\end{array}$ & $\begin{array}{l}1 \\
\mathrm{mg} / \mathrm{L}\end{array}$ & $\begin{array}{l}5 \\
\mathrm{mg} / \mathrm{L}\end{array}$ & $\begin{array}{l}10 \\
\mathrm{mg} / \mathrm{L}\end{array}$ & Control & $\begin{array}{l}0.1 \\
\mathrm{mg} / \mathrm{L}\end{array}$ & $\begin{array}{l}1 \\
\mathrm{mg} / \mathrm{L}\end{array}$ & $\begin{array}{l}5 \\
\mathrm{mg} / \mathrm{L}\end{array}$ & $\begin{array}{l}10 \\
\mathrm{mg} / \mathrm{L}\end{array}$ \\
\hline MDA & 1.06 & 2.25 & 0.63 & 0.00 & 0.25 & 0.27 & 0.45 & 1.27 & 0.09 & 0.00 \\
\hline $\mathrm{H}_{2} \mathrm{O}_{2}$ & 0.00 & 0.00 & 1.80 & 1.27 & 1.67 & 0.00 & 0.69 & 1.58 & 2.16 & 2.21 \\
\hline SOD & 0.00 & 1.43 & 0.92 & 1.63 & 3.04 & 1.06 & 0.00 & 0.84 & 1.21 & 1.74 \\
\hline CAT & 0.58 & 0.00 & 1.54 & 2.16 & 3.00 & 0.00 & 0.09 & 0.81 & 2.14 & 1.76 \\
\hline POD & 0.00 & 0.06 & 0.14 & 2.07 & 3.05 & 0.00 & 0.09 & 1.56 & 1.98 & 2.05 \\
\hline PPO & 0.00 & 1.80 & 1.80 & 1.56 & 2.04 & 0.00 & 1.46 & 2.21 & 0.50 & 1.25 \\
\hline APX & 0.00 & 0.52 & 0.66 & 3.07 & 0.46 & 0.12 & 0.00 & 0.34 & 0.75 & 2.18 \\
\hline AsA & 0.00 & 0.13 & 0.51 & 1.93 & 2.45 & 0.00 & 0.25 & 1.03 & 1.54 & 2.64 \\
\hline GSH & 0.16 & 0.00 & 0.03 & 0.82 & 2.97 & 0.15 & 0.21 & 0.37 & 0.00 & 1.56 \\
\hline IBR value & 0.06 & 0.36 & 2.00 & 8.23 & 12.86 & 0.01 & 0.19 & 3.44 & 3.91 & 8.24 \\
\hline
\end{tabular}

\section{Discussion}

Many studies reported that seed germination of crops was insensitive to various antibiotics such as fluoroquinolones, lincosamides, macrolides, sulfonamides, tetracyclines (Hillis et al. 2011; Bellino et al. 2018; Pan and Chu 2016). In our study, ciprofloxacin employed did not influence both the germination rate and rooting rate of $P$. crispus and $H$. verticillata, which suggested that the effects of antibiotics on turion germination were nearly not available. Some cellular processes might be negatively affected by antibiotics (Gambonnet et al. 2001), but germination was considered as a highly conserved process during which sufficient nutrients, carbohydrates, and proteins were stored and available for the appearance of germ or radicle (Hillis et al. 2011). Turions functionally resemble seeds, serving multiple functions including carbohydrate storage, propagation, and dispersal (Jian et al. 2003). In this light, germination and rooting of turions of $P$. crispus and $H$. verticillata could be considered tolerant to ciprofloxacin exposure. Notably, without impacts on germination and rooting rates, ciprofloxacin could accelerate or delay the germination and rooting process, which were assessed by germination time and rooting time. Indeed, we found ciprofloxacin at $0.1 \mathrm{mg} / \mathrm{L}$ significantly accelerated turion germination of $H$. verticillata, with slight accelerations at higher concentrations. Similar results have also been found in maize seeds, where ciprofloxacin was proved to induced $\mathrm{H}_{2} \mathrm{O}_{2}$ production by inhibiting the activity of mitochondrial Complex III (Gomes et al. 2019). Consequently, elevated $\mathrm{H}_{2} \mathrm{O}_{2}$ promoted the signaling for germination and accelerate seed germination of maize (Gomes et al. 2019; Wojtyla et al. 2016). However, though phytochrome-induced transmissible signals, low molecular mass carbohydrates and phytohormones were proposed to be the 
possible signals regulating turion germination (Tirlapur et al. 1999; Ley et al. 1997), no specific metabolic changes during the breaking period could be served as metabolic signals (Adamec, 2018). Taken ciprofloxacin as an inhibitor of mitochondrial Complex III (Gomes et al. 2019), further studies on energy metabolism, together with saccharides contents might help to explain beneficial effects of ciprofloxacin on turion germination. Rooting, as the first step of development of the root system, plays an essential role for plant life. Initiation of roots of higher plants were mediated by phytohormones and many external factors such as light, temperature, nutrients and cutting (Xuan et al. 2012). For example, as an important signal for cell division, elongation and differentiation, auxin was highly involved in root primordia formation (Pagnussat et al. 2004). Additionally, nitric oxide was a main factor that mediated the auxin response during rooting process (Pagnussat et al. 2004). Ciprofloxacin has been proved to disturb cellular nitric oxide production (Aiassa et al. 2006; Kolios et al. 2006; Adedara et al. 2021), resulting in lipid, protein, and nucleic acids modification and cellular chaos. Our results showed that ciprofloxacin especially at higher concentrations (5-10 mg/L) had retarding effects on the rooting process of $H$. verticillata and P. crispus, and these might because ciprofloxacin disturbed the cellular nitric oxide level, which could further impact auxin response as well as rooting performance of turions.

Regardless of exposure time, RTI of both species decreased significantly with increasing ciprofloxacin concentrations, indicating toxicity of ciprofloxacin on RTI was concentration-dependent. Unlike RTI, STI of $P$. crispus at $7 \mathrm{~d}$ was not influenced by ciprofloxacin treatment. What's more, ciprofloxacin promoted STI of $H$. verticillata at 14-21d. This might because ciprofloxacin addition provided more carbon and nitrogen sources for plant growth (Mao et al. 2021), resulting in but better growth performance and higher STI over these short exposures. However, after longer exposures, STI of both species also decreased with increasing ciprofloxacin concentrations, indicating hysteresis effects of ciprofloxacin toxicity on STI. RTI of $P$. crispus treated with $1-5 \mathrm{mg} / \mathrm{L}$ ciprofloxacin and $H$. verticillata treated with $0.1-5 \mathrm{mg} / \mathrm{L}$ ciprofloxacin decreased significantly over exposure time, with STI of both species in 1-5 $\mathrm{mg} / \mathrm{L}$ treatments decreasing significantly with time prolonging. These results suggested seedling tolerance of $H$. verticillata and $P$. crispus to ciprofloxacin decreased over time, and both RTI and STI were reliable and sensitive indicators for ciprofloxacin toxicity on plant early establishment. Moreover, considering that IC50 values for RTI were lower than those for STI, we concluded that RTI was more sensitive than STI, regardless of species and exposure time. Previous studies also demonstrated high sensitivity of root elongation to antibiotics including tetracycline, sulfamethazine, norfloxacin, erythromycin and chloramphenicol compared to shoot elongation (Pan and Chu 2016). Root number and shoot number could reflect seedling growth status directly. Regardless of exposure time, root number of both species decreased significantly with increasing ciprofloxacin concentrations, while shoot number was less affected. Roots are the main organ for absorbing antibiotics and growth of roots was more severely inhibited than that of shoots (Guo et al. 2020), presumably because seedlings of $H$. verticillata and $P$. crispus mainly relied on their roots to absorb ciprofloxacin. Accordingly, reductions in root number and root biomass might help to avoid the absorption of larger quantities of toxicants and thus reducing damages to seedling growth. Regardless of ciprofloxacin concentration, shoot number of $H$. verticillata increased over time, while $P$. crispus showed no such growth in its shoot. These results indicated better adaptability of $H$. verticillata than $P$. crispus under ciprofloxacin exposure. 
With RTI, STI and root number decreasing with rising ciprofloxacin concentrations and time prolonging, shoot and root biomass accumulations of both $\mathrm{H}$. verticillata and $P$. crispus were evidently inhibited. On one hand, this may be explained by toxicity effect of ciprofloxacin on photosynthetic pigments. Fluoroquinolone antibiotics were reported to disrupt chloroplast structure and eventually resulted in reductions of pigment contents as well as etiolation of plant leaves (Liu et al. 2021; Yan et al. 2019). Furthermore, damaged leave functional traits would inevitably impact plant photosynthesis and subsequent growth processes. On the other hand, plants tend to defense against stress but actively inhibit growth related metabolisms to respond to adverse environmental conditions (Zhang et al. 2020). And worse growth performance of $P$. crispus and $H$. verticillata might be related to plant defense against oxidative stress induced by ciprofloxacin, during which cellular energy was highly consumed and thus energy available for growth process might be limited.

Ciprofloxacin could cause oxidative stress by inhibiting mitochondria electron transport chain, leading to cellular ROS accumulation and oxidative damages (Gomes et al. 2019). For example, ROS could attack and degrade the cell membrane to produce MDA, which functioned as a proxy of lipid peroxidation. No lipid peroxidation was observed in both species under ciprofloxacin exposure. However, $\mathrm{H}_{2} \mathrm{O}_{2}$ contents of $P$. crispus and $H$. verticillata were elevated by $16.02 \%-27.08 \%$ and by $29.82 \%-42.06 \%$, respectively. Antibiotics like fluoroquinolones could induce hormesis in various plant species and cause promotions of several physiological, cellular and growth traits of plants, where the observed stimulatory responses were generally lower than 1.5 times of the control (Agathokleous et al. 2018). Thus, the $\mathrm{H}_{2} \mathrm{O}_{2}$ levels in $P$. crispus and $\mathrm{H}$. verticillata were probably below those at which $\mathrm{H}_{2} \mathrm{O}_{2}$ would become phytotoxic. Though with oxidative cellular toxicity, $\mathrm{H}_{2} \mathrm{O}_{2}$ is an important signal molecule in modulating signaling networks that regulates plant growth, development and stress responses (Mittler et al. 2004).

To cope with oxidative event, plants are capable of activating their ROS detoxification systems, the enzymatic and non-enzymatic antioxidants. Firstly, superoxide anions were transferred into $\mathrm{H}_{2} \mathrm{O}_{2}$ by SOD, and then $\mathrm{H}_{2} \mathrm{O}_{2}$ could be further transferred into $\mathrm{O}_{2}$ by CAT, POD and APX (Yan et al. 2019). PPO could protect plant from photo-oxidative damages by catalyzing the oxidation of phenols (Boeckx et al. 2015). Both AsA and GSH are powerful antioxidant compounds in scavenging cellular ROS directly, by which plants could enhance their antioxidant capacity (Mittler et al. 2004). In P. crispus, activated SOD activity produced large quantities of $\mathrm{H}_{2} \mathrm{O}_{2}$. Meanwhile, POD and APX activities, AsA and GSH contents were significantly elevated. These antioxidants worked well in removing ROS induced by ciprofloxacin, thereby controlling $\mathrm{H}_{2} \mathrm{O}_{2}$ levels tightly and maintaining stability of cell membranes in P. crispus. However, CAT and PPO activities responded negatively under ciprofloxacin exposure. As a photosensitizer, CAT would be likely inactive once photosynthetic pigment contents were reduced (Smirnoff 1995), which was in line with the observed reductions in pigments contents. Decreased activity of PPO has been considered as one of the outcomes of plant enhanced antioxidant capacity (Boeckx et al. 2015), indicating the local oxygen was maintained at levels that could not cause photoinhibition or oxidative damages. For $H$. verticillata, SOD activity increased slightly but not significantly in $5-10 \mathrm{mg} / \mathrm{L}$ treatments. At the same time, activated POD and APX could remove $\mathrm{H}_{2} \mathrm{O}_{2}$ catalyzed by SOD activity. Compared with $P$. crispus, the effects of SOD in detoxifying ROS in $\mathrm{H}$. verticillata was relatively weaker. This might because the quantities of superoxide anions were beyond the capacity of SOD, which would inhibit the outputs of this enzyme. Likely, as a 
compensative response, PPO activity was significantly activated, indicating high amounts of oxygen were removed by the oxidation of phenolic compounds. Additionally, AsA and GSH contents increased markedly especially at high ciprofloxacin concentrations, indicating their vital roles in quenching ROS and protecting cells from oxidative damages. To conclude, firstly, though $P$. crispus and $H$. verticillata employed different antioxidant enzymes to prevent oxidative damages, AsA and GSH worked well in ROS detoxification in both species. Both AsA and GSH are water soluble and easily accessible with potent antioxidant properties. Furthermore, addition of exogenous antioxidants could increase their endogenous contents and enhance plant antioxidant capacity under stress conditions (Akram et al. 2017). Therefore, our results might provide some research ideas for alleviation of phytotoxicity of ciprofloxacin. Secondly, the POD $-\mathrm{H}_{2} \mathrm{O}_{2}$ decomposition system was involved in the degradation of chlorophylls (Kar and Choudhuri 1987), and the observed elevations of POD activity could be invoked to account for the reductions of chlorophylls contents in both species. Thirdly, under exposure to antibiotics like ciprofloxacin, defense against oxidative stress could elevate cellular energy consumption, causing lower amounts of energy available for growth (Aderemi et al. 2018). To speculate, P. crispus and $H$. verticillata might allocate much more cellular energy to detoxify ROS to maintain physiological stability, resulting in growth inhibitions related to insufficient energy supply.

IBR levels were employed to compare stress degree related to various environmental conditions, where a higher IBR level indicated more serious impact in an organism (Kim et al. 2010). We found IBR values increased with rising ciprofloxacin concentrations. That was, the higher the ciprofloxacin concentrations were, the more serious the damage to both submerged plants. These results were consistent with those of seedling tolerance, photosynthetic pigment contents and biomass accumulations, suggesting toxicity effects of ciprofloxacin on these two species were concentration-dependent. On the other hand, the selected biomarkers responded efficiently to ciprofloxacin pollution, and the IBR could serve as a reliable parameter for quantitative evaluation of the toxicological effects of ciprofloxacin toward aquatic plants.

\section{Conclusion}

Germination rate and rooting rate of turions of $P$. crispus and $H$. verticillata were not impacted by ciprofloxacin employed in this study. However, ciprofloxacin delayed rooting process of both species. Both RTI and STI were reliable and sensitive endpoints to assess ciprofloxacin toxicity on seedling development. Additionally, roots came to be more sensitive than shoots under ciprofloxacin treatment. The lowest toxicity threshold (IC50) values of ciprofloxacin based on seedling tolerance of $P$. crispus and $H$. verticillata were $2.203 \mathrm{mg} / \mathrm{L}$ and $2.635 \mathrm{mg} / \mathrm{L}$, respectively. With better growth performance of shoots, $H$. verticillata appeared to be more tolerant to ciprofloxacin exposure than P. crispus, which might provide information for the selection of aquatic plant species for restoration of water bodies polluted by ciprofloxacin. Ciprofloxacin induced oxidative stress and activated the antioxidant system of both species. Key antioxidant enzymes for ROS detoxication differed between $P$. crispus and $H$. verticillata, while non-enzymatic antioxidants (AsA and GSH) functioned well in both species, which might provide valuable research ideas for alleviation of ciprofloxacin toxicity. As the first study that investigated ciprofloxacin toxicity on germination and seedling development of submerged turions, this research might provide a new perspective to reveal the aquatic environments risks of antibiotics pollution. Stress levels suffered by both plants were enhanced with rising 
drug concentrations, suggesting IBR could serve as a reliable parameter for quantitative evaluation of the toxicological effects of ciprofloxacin toward aquatic plants. Lastly, to better predict population dynamics and improve effectiveness of vegetation restoration, the combined effects of antibiotics and other pollutants on propagule germination and early establishment of aquatic plants should be further studied.

\section{Declarations}

\section{Funding}

This research was funded by the National Natural Science Foundation of China (No. 31270410 and No. 30970303).

\section{Author contributions}

Pei Fan performed the study, analyzed the data and wrote the paper. Chunhua Liu reviewed and edited the paper. Zhen Ke and Wei Zhou performed the sample collection and sample processing. Zhonghua Wu provided experimental supervision.

\section{Data availability}

All the Data for this study are available from Zhonghua Wu (wuzhonghua@whu.edu.cn) and Pei Fan (fanpei@whu.edu.cn).

\section{Ethics declarations}

\section{Ethics approval and consent to participate}

Not applicable.

\section{Consent for publication}

Not applicable.

\section{Competing interests}

All authors declared that there were no competing interests.

\section{References}

1. Adamec $L$ (2008) Respiration of turions and winter apices in aquatic carnivorous plants. Biologia 63:515-520. https://doi.org/10.2478/s11756-008-0073-4

2. Adamec $L$ (2018) Ecophysiological characteristics of turions of aquatic plants: A review. Aquat Bot 148:64-77. https://doi.org/10.1016/j.aquabot.2018.04.011

3. Adedara IA, Godswill US, Mike MA, Afolabi BA, Amorha CC, Sule J, Rocha JBT, Farombi EO (2021) Chronic ciprofloxacin and atrazine co-exposure aggravates locomotor and exploratory deficits in non- 
target detritivore speckled cockroach (Nauphoeta cinerea). Environ Sci Pollut R 28:25680-25691. https://doi.org/10.1007/s11356-021-12460-5

4. Adeleye AS, Xue J, Zhao Y, Taylor AA, Zenobio JE, Sun Y, Han Z, Salawu OA, Zhu Y (2022) Abundance, fate, and effects of pharmaceuticals and personal care products in aquatic environments. J Hazard Mater 424:127284. https://doi.org/10.1016/j.jhazmat.2021.127284

5. Aderemi AO, Novais SC, Lemos MFL, Alves LM, Hunter C, Pahl O (2018) Oxidative stress responses and cellular energy allocation changes in microalgae following exposure to widely used human antibiotics. Aquat Toxicol 203:130-139. https://doi.org/10.1016/j.aquatox.2018.08.008

6. Agathokleous E, Kitao M, Calabrese EJ (2018) Human and veterinary antibiotics induce hormesis in plants: Scientific and regulatory issues and an environmental perspective. Environ Int 120:489-495. https://doi.org/10.1016/j.envint.2018.08.035

7. Aiassa V, Barnes Al, Albesa I (2006) Action of ciprofloxacin on planktonic bacteria and biofilm of Proteus mirabilis. Biofilms 3:11-17. https://doi.org/10.1017/S1479050507002086

8. Akram NA, Shafiq F, Ashraf M (2017) Ascorbic acid-A potential oxidant scavenger and its role in plant development and abiotic stress tolerance. Front Plant Sci 8:1-17. https://doi.org/10.3389/fpls.2017.00613

9. Bellino A, Lofrano G, Carotenuto M, Libralato G, Baldantoni D (2018) Antibiotic effects on seed germination and root development of tomato (Solanum lycopersicum L.). Ecotox Environ Safe 148:135-141. https://doi.org/10.1016/j.ecoenv.2017.10.006

10. Bertrand L, Monferrán MV, Valdés ME, Amé MV (2019) Usefulness of a freshwater macrophyte (Potamogeton pusillus) for an environmental risk assessment in a multi-source contaminated basin. Chemosphere 222:1003-1016. https://doi.org/10.1016/j.chemosphere.2019.02.018

11. Boeckx T, Winters AL, Webb KJ, Kingston-Smith AH (2015) Polyphenol oxidase in leaves: is there any significance to the chloroplastic localization? J Exp Bot 66:3571-3579.

https://doi.org/10.1093/jxb/erv141

12. Bornette G, Puijalon S (2010) Response of aquatic plants to abiotic factors: a review. Aquat Sci 73:114. https://doi.org/10.1007/s00027-010-0162-7

13. Boy-Roura M, Mas-Pla J, Petrovic M, Gros M, Soler D, Brusi D, Menció A (2018) Towards the understanding of antibiotic occurrence and transport in groundwater: Findings from the Baix Fluvià alluvial aquifer (NE Catalonia, Spain). Sci Total Environ 612:1387-1406. https://doi.org/10.1016/j.scitotenv.2017.09.012

14. Bradford MM (1976) A rapid and sensitive method for the quantitation quantities microgram principle of protein-dye binding. Anal Biochem 72:248-254. https://doi.org/10.1016/0003-2697(76)90527-3

15. Cang J, Zhao HJ (2013) Experimental Course of Plant Physiology. Higher Education press, Peking

16. Chen Q, Zhang X, Liu Y, Wei J, Shen W, Shen Z, Cui J (2017) Hemin-mediated alleviation of zinc, lead and chromium toxicity is associated with elevated photosynthesis, antioxidative capacity; suppressed metal uptake and oxidative stress in rice seedlings. Plant Growth Regul 81:253-264. https://doi.org/10.1007/s10725-016-0202-y 
17. Chen Y, Chen H, Zhang L, Jiang Y, Gin K, He Y (2018) Occurrence, distribution, and risk assessment of antibiotics in a subtropical river-reservoir system. Water-Sui 10:104.

https://doi.org/10.3390/w10020104

18. Chen Y, Xie Q, Wan J, Yang S, Wang Y, Fan H (2020) Occurrence and risk assessment of antibiotics in multifunctional reservoirs in Dongguan, China. Environ Sci Pollut R 27:13565-13574.

https://doi.org/10.1007/s11356-019-07436-5

19. Ebert I, Bachmann J, Kühnen U, Küster A, Kussatz C, Maletzki D, Schlüter C (2011) Toxicity of the fluoroquinolone antibiotics enrofloxacin and ciprofloxacin to photoautotrophic aquatic organisms. Environ Toxicol Chem 30:2786-2792. https://doi.org/10.1002/etc.678

20. Ellis RH, Roberts EH (1981) The quantification of ageing and survival in orthodox seeds. Seed Sci Technol 9:373-409

21. Fick J, Soderstrom H, Lindberg RH, Phan C, Tysklind M, Larsson DG (2009) Contamination of surface, ground, and drinking water from pharmaceutical production. Environ Toxicol Chem 28:2522-2527. https://doi.org/10.1897/09-073.1

22. Gambonnet B, Jabrin S, Ravanel S, Karan M, Douce R, Rébeillé F (2001) Folate distribution during higher plant development. J Sci Food Agr 81:835-841. https://doi.org/10.1002/jsfa.870

23. Gomes MP, Richardi VS, Bicalho EM, Da Rocha DC, Navarro-Silva MA, Soffiatti P, Garcia QS, Sant'AnnaSantos BF (2019) Effects of ciprofloxacin and roundup on seed germination and root development of maize. Sci Total Environ 651:2671-2678. https://doi.org/10.1016/j.scitotenv.2018.09.365

24. Guo X, Liu M, Zhong H, Li P, Zhang C, Wei D, Zhao T (2020) Responses of the growth and physiological characteristics of Myriophyllum aquaticum to coexisting tetracyclines and copper in constructed wetland microcosms. Environ Pollut 261:114204. https://doi.org/10.1016/j.envpol.2020.114204

25. Ha M, Pflugmacher S (2013) Time-dependent alterations in growth, photosynthetic pigments and enzymatic defense systems of submerged Ceratophyllum demersum during exposure to the cyanobacterial neurotoxin anatoxin-a. Aquat Toxicol 138-139:26-34. https://doi.org/10.1016/j.aquatox.2013.04.007

26. Han QF, Zhao S, Zhang XR, Wang XL, Song C, Wang SG (2020) Distribution, combined pollution and risk assessment of antibiotics in typical marine aquaculture farms surrounding the Yellow Sea, North China. Environ Int 138:105551. https://doi.org/10.1016/j.envint.2020.105551

27. Hillis DG, Fletcher J, Solomon KR, Sibley PK (2011) Effects of ten antibiotics on seed germination and root elongation in three plant species. Arch Environ Con Tox 60:220-232. https://doi.org/10.1007/s00244-010-9624-0

28. Hoagland DR, Arnon DI (1950) The water-culture method for growing plants without soil. Calif Agric Exp Stn Circ 347:1-32

29. Hua Z, Li X, Zhang J, Gu L (2022) Removal potential of multiple perfluoroalkyl acids (PFAAs) by submerged macrophytes in aquatic environments: Tolerance of Vallisneria natans and PFAA removal in submerged macrophyte-microbiota systems. J Hazard Mater 424:127695.

https://doi.org/10.1016/j.jhazmat.2021.127695

Page 18/26 
30. Jampeetong A, Brix H (2009) Effects of $\mathrm{NaCl}$ salinity on growth, morphology, photosynthesis and proline accumulation of Salvinia natans. Aquat Bot 91:181-186.

https://doi.org/10.1016/j.aquabot.2009.05.003

31. Jian Y, Li B, Wang J, Chen J (2003) Control of turion germination in Potamogeton crispus. Aquat Bot 75:59-69. https://doi.org/10.1016/S0304-3770(02)00165-1

32. Kar RK, Choudhuri MABU (1987) Possible mechanisms of light induced chlorophyll degradation in senescing leaves of Hydrilla verticillata. Physiol Plant 70:729-734. https://doi.org/10.1111/j.13993054.1987.tb04331.x

33. Kim WK, Lee SK, Jung J (2010) Integrated assessment of biomarker responses in common carp (Cyprinus carpio) exposed to perfluorinated organic compounds. J Hazard Mater 180:395e400. https://doi.org/10.1016/j.jhazmat.2010.04.044

34. Koczura R, Mokracka J, Jabłońska L, Gozdecka E, Kubek M, Kaznowski A (2012) Antimicrobial resistance of integron-harboring Escherichia coli isolates from clinical samples, wastewater treatment plant and river water. Sci Total Environ 414:680-685. https://doi.org/10.1016/j.scitotenv.2011.10.036

35. Kolios G, Manousou P, Bourikas L, Notas G, Tsagarakis N, Mouzas I, Kouroumalis E (2006) Ciprofloxacin inhibits cytokine-induced nitric oxide production in human colonic epithelium. Eur J Clin Invest 36:720729. https://doi.org/10.1111/j.1365-2362.2006.01710.x

36. Ley S, Dölger K, Appenroth KJ (1997) Carbohydrate metabolism as a possible physiological modulator of dormancy in turions of Spirodela polyrhiza (L.) Schleiden. Plant Sci 129:1-7. https://doi.org/10.1016/S0168-9452(97)00151-9

37. Li H, Li Y, Huang D, Zhang L, Lu J, Zhang J (2021) The response mechanism of Hydrilla verticillata and leaf epiphytic biofilms to depth and nutrient removal. Environ Sci Pollut R 28:49032-49041. https://doi.org/10.1007/s11356-021-14131-x

38. Lichtenthaler $\mathrm{H}$, Wellburn $\mathrm{A}$ (1983) Determinations of total carotenoids and chlorophylls $\mathrm{a}$ and $\mathrm{b}$ of leaf extracts in different solvents. Biochem Soc T 11:591-592. https://doi.org/10.1042/bst0110591

39. Liu L, Liu Y, Liu C, Wang Z, Dong J, Zhu G, Huang X (2013) Potential effect and accumulation of veterinary antibiotics in Phragmites australis under hydroponic conditions. Ecol Eng 53:138-143. https://doi.org/10.1016/j.ecoleng.2012.12.033

40. Liu X, Lv Y, Gao S, Xu K (2021) Ofloxacin induces etiolation in Welsh onion leaves. Chemosphere 267:128918. https://doi.org/10.1016/j.chemosphere.2020.128918

41. Liu X, Zhang S, Shan X, Christie P (2007) Combined toxicity of cadmium and arsenate to wheat seedlings and plant uptake and antioxidative enzyme responses to cadmium and arsenate cocontamination. Ecotox Environ Safe 68:305-313. https://doi.org/10.1016/j.ecoenv.2006.11.001

42. Lu S, Lin C, Lei K, Xin M, Gu X, Lian M, Wang B, Liu X, Ouyang W, He M (2022) Profiling of the spatiotemporal distribution, risks, and prioritization of antibiotics in the waters of Laizhou Bay, northern China. J Hazard Mater 424:127487. https://doi.org/10.1016/j.jhazmat.2021.127487

43. Mao Y, Yu Y, Ma Z, Li H, Yu W, Cao L, He Q (2021) Azithromycin induces dual effects on microalgae: Roles of photosynthetic damage and oxidative stress. Ecotox Environ Safe 222:112496. https://doi.org/10.1016/j.ecoenv.2021.112496

Page 19/26 
44. Marchant J (2018) When antibiotics turn toxic. Nature 55:431-433. https://doi.org/10.1038/d41586018-03267-5

45. Mittler R, Vanderauwera S, Gollery M, Van Breusegem F (2004) Reactive oxygen gene network of plants. Trends Plant Sci 9:490-498. https://doi.org/10.1016/j.tplants.2004.08.009

46. Özgencil OK, Beklioğlu M, Özkan K, Tavşanoğlu Ç, Fattorini N (2020) Changes in functional composition and diversity of waterbirds: The roles of water level and submerged macrophytes. Freshw Biol 65:1845-1857. https://doi.org/10.1111/fwb.13531

47. Pagnussat GC, Lanteri ML, Lombardo MC, Lamattina L (2004) Nitric oxide mediates the indole acetic acid induction activation of a mitogen-activated protein kinase cascade involved in adventitious root development. Plant Physiol 135:279-286. https://doi.org/10.1104/pp.103.038554

48. Pan C, Bao Y, Xu B (2020) Seasonal variation of antibiotics in surface water of Pudong New Area of Shanghai, China and the occurrence in typical wastewater sources. Chemosphere 239:124816. https://doi.org/10.1016/j.chemosphere.2019.124816

49. Pan M, Chu LM (2016) Phytotoxicity of veterinary antibiotics to seed germination and root elongation of crops. Ecotox Environ Safe 126:228-237. https://doi.org/10.1016/j.ecoenv.2015.12.027

50. Phillips G, Willby N, Moss B (2016) Submerged macrophyte decline in shallow lakes: What have we learnt in the last forty years? Aquat Bot 135:37-45. https://doi.org/10.1016/j.aquabot.2016.04.004

51. Ren W, Wen Z, Cao Y, Wang H, Yuan C, Zhang X, Ni L, Xie P, Cao T, Li K, Jeppesen E (2022) Cascading effects of benthic fish impede reinstatement of clear water conditions in lakes: A mesocosm study. J Environ Manage 301:113898. https://doi.org/10.1016/j.jenvman.2021.113898

52. Robinson AA, Belden JB, Lydy MJ (2005) Toxicity of fluoroquinolone antibiotics to aquatic organisms. Environ Toxicol Chem 24:423-430. https://doi.org/10.1897/04-210R.1

53. Rossato L, MacFarlane J, Whittaker M, Pudmenzky A, Doley D, Schmidt S, Monteiro MJ (2011) Metalbinding particles alleviate lead and zinc toxicity during seed germination of metallophyte grass Astrebla lappacea. J Hazard Mater 190:772-779. https://doi.org/10.1016/j.jhazmat.2011.03.116

54. Shi HT (2016) Experimental Guidance of Plant Stress Physiology. Science Press, Peking

55. Smirnoff N (1995) Antioxidant systems and plant response to the environment. BIOS Scientific Publishers, Oxford

56. Song X, Wang Z, Xiao B, Li E, Wang X (2017) Growth of Potamogeton crispus L. from turions in darkness: Implications for restoring submerged plants in eutrophic lakes. Ecol Eng 101:255-260. https://doi.org/10.1016/j.ecoleng.2017.01.035

57. Tirlapur UK, Dahse I, Probandt R, Fischer W, Appenroth KJJU (1999) Phytochrome-induced transmissible signal elicits germination response in turions of Spirodela polyrhiza. Physiol Plant 105:539-545. https://doi.org/10.1034/j.1399-3054.1999.105320.x

58. Wang J, Song Y, Wang G (2017) Causes of large Potamogeton crispus L. population increase in Xuanwu Lake. Environ Sci Pollut R 24:5144-5151. https://doi.org/10.1007/s11356-016-6514-7

59. Wojtyla L, Lechowska K, Kubala S, Garnczarska M (2016) Different modes of hydrogen peroxide action during seed germination. Front Plant Sci 7:66. https://doi.org/10.3389/fpls.2016.00066 
60. Wu H, Hao B, Jo H, Cai Y (2021) Seasonality and species specificity of submerged macrophyte biomass in shallow lakes under the influence of climate warming and eutrophication. Front Plant Sci 12. https://doi.org/10.3389/fpls.2021.678259

61. Wu Q, Xiao S, Pan C, Yin C, Wang Y, Yu K (2022) Occurrence, source apportionment and risk assessment of antibiotics in water and sediment from the subtropical Beibu Gulf, South China. Sci Total Environ 806:150439. https://doi.org/10.1016/j.scitotenv.2021.150439

62. Xuan W, Xu S, Li M, Han B, Zhang B, Zhang J, Lin Y, Huang J, Shen W, Cui J (2012) Nitric oxide is involved in hemin-induced cucumber adventitious rooting process. J Plant Physiol 169:1032-1039. https://doi.org/10.1016/j.jplph.2012.02.021

63. Yan Y, Xu X, Shi C, Yan W, Zhang L, Wang G (2019) Ecotoxicological effects and accumulation of ciprofloxacin in Eichhornia crassipes under hydroponic conditions. Environ Sci Pollut Res Int 26:3034830355. https://doi.org/10.1007/s11356-019-06232-5

64. Yan Z, Wang Q, Li Y, Wu L, Wang J, Xing B, Yu D, Wang L, Liu C (2021) Combined effects of warming and nutrient enrichment on water properties, growth, reproductive strategies and nutrient stoichiometry of Potamogeton crispus. Environ Exp Bot 190:104572.

https://doi.org/10.1016/j.envexpbot.2021.104572

65. Yang Y, Wan K, Yang Z, Li D, Li G, Zhang S, Wang L, Yu X (2020) Inactivation of antibiotic resistant Escherichia coli and degradation of its resistance genes by glow discharge plasma in an aqueous solution. Chemosphere 252:126476. https://doi.org/10.1016/j.chemosphere.2020.126476

66. Yu H, Qi W, Cao X, Wang Y, Li Y, Xu Y, Zhang X, Peng J, Qu J (2022) Impact of microplastics on the foraging, photosynthesis and digestive systems of submerged carnivorous macrophytes under low and high nutrient concentrations. Environ Pollut 292:118220. https://doi.org/10.1016/j.envpol.2021.118220

67. Yuan DY, Meng X, Duan CQ, Wei ZH, Gao W, Chang JJ, Lv XJ, Pan Y (2018) Effects of water exchange rate on morphological and physiological characteristics of two submerged macrophytes from Erhai Lake. Ecol Evol 8:12750-12760. https://doi.org/10.1002/ece3.4703

68. Zhang H, Zhao Y, Zhu JK (2020) Thriving under stress: How plants balance growth and the stress response. Dev Cecc 55:529-543. https://doi.org/10.1016/j.devcel.2020.10.012

69. Zhang J, Huang D, Deng H, Zhang J (2021) Responses of submerged plant Vallisneria natans growth and leaf biofilms to water contaminated with microplastics. Sci Total Environ 151750. https://doi.org/10.1016/j.scitotenv.2021.151750

70. Zhang YS, Huang X, Chen YF (2009) Experimental Course of Plant Physiology. Higher Education press, Peking

\section{Figures}



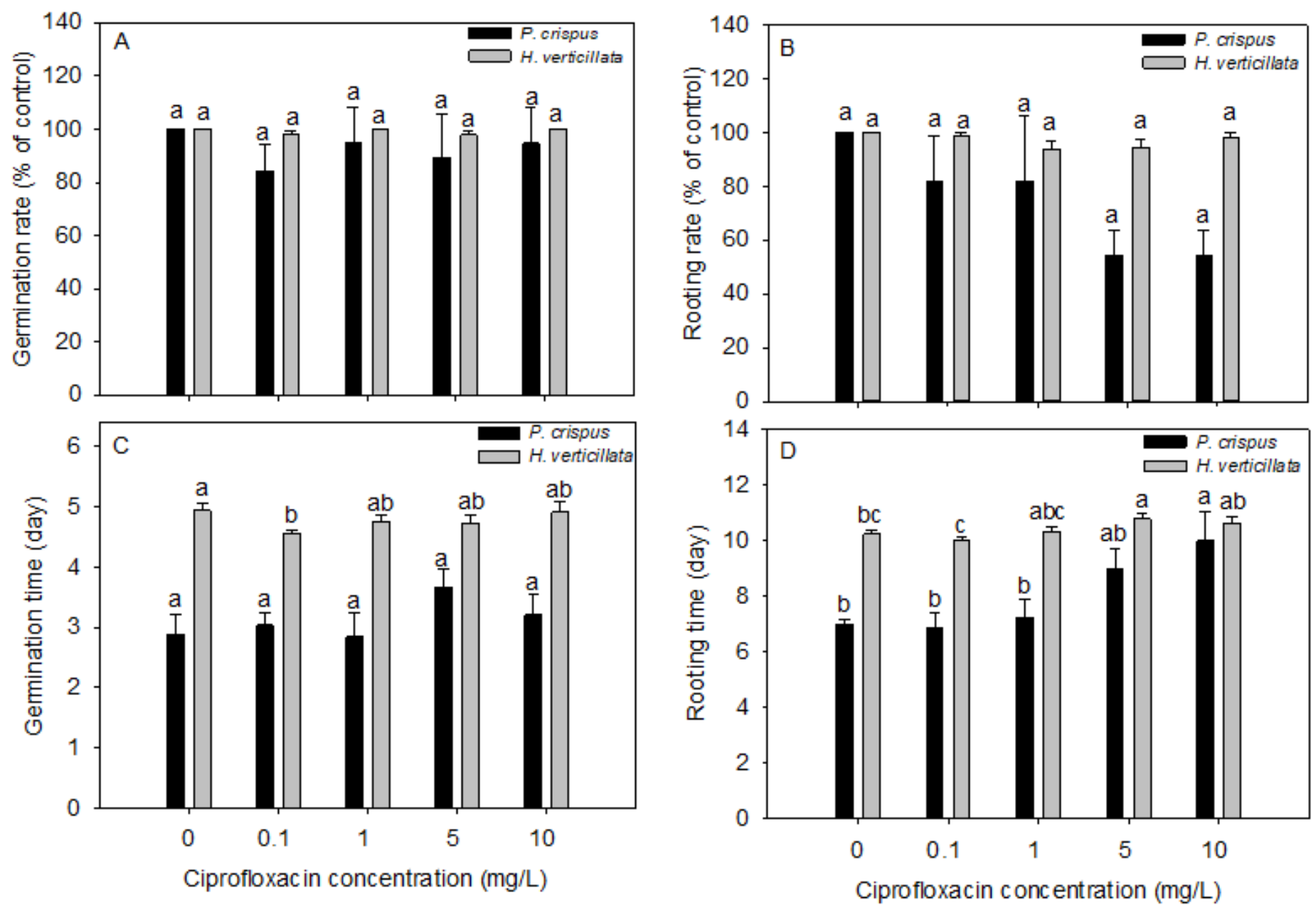

Figure 1

Germination rate (A), rooting rate (B), germination time (C) and rooting time (D) of $P$. crispus and $H$. verticillata under ciprofloxacin exposure. Bars represent the mean of five replicates \pm standard deviation. Different letters indicate significant differences among different treatments for a specific plant species $(p<$ 0.05 , LSD test). 

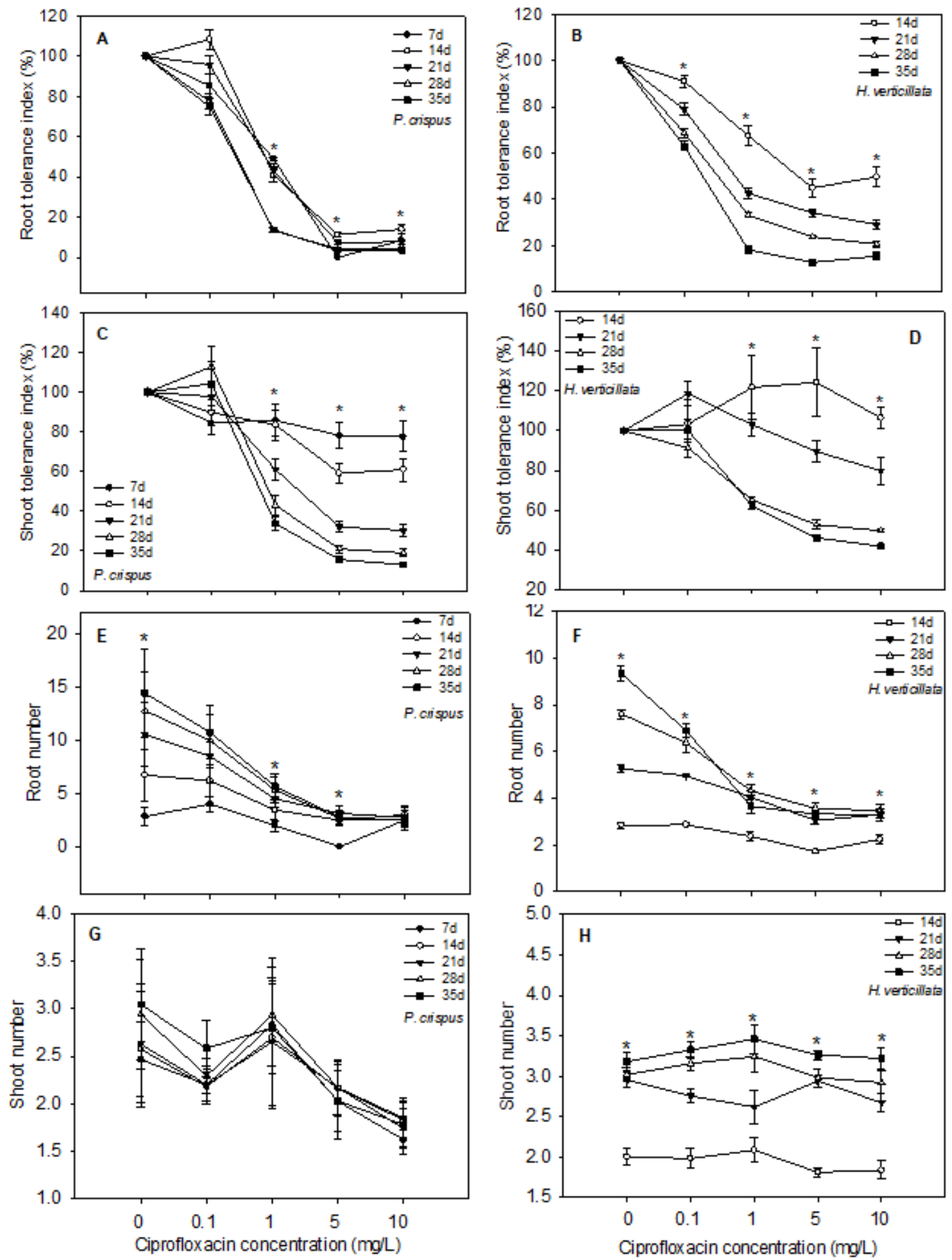

Figure 2

Root tolerance index $(A, B)$, shoot tolerance index $(C, D)$, root number $(E, F)$ and shoot number $(G, H)$ of $P$. crispus and $H$. verticillata after 7, 14, 21, 28 and 35d of ciprofloxacin exposure. Bars represent the mean of five replicates \pm standard deviation. Stars indicate significant differences among different time points at the same ciprofloxacin concentration ( $p<0.05$, LSD test). 

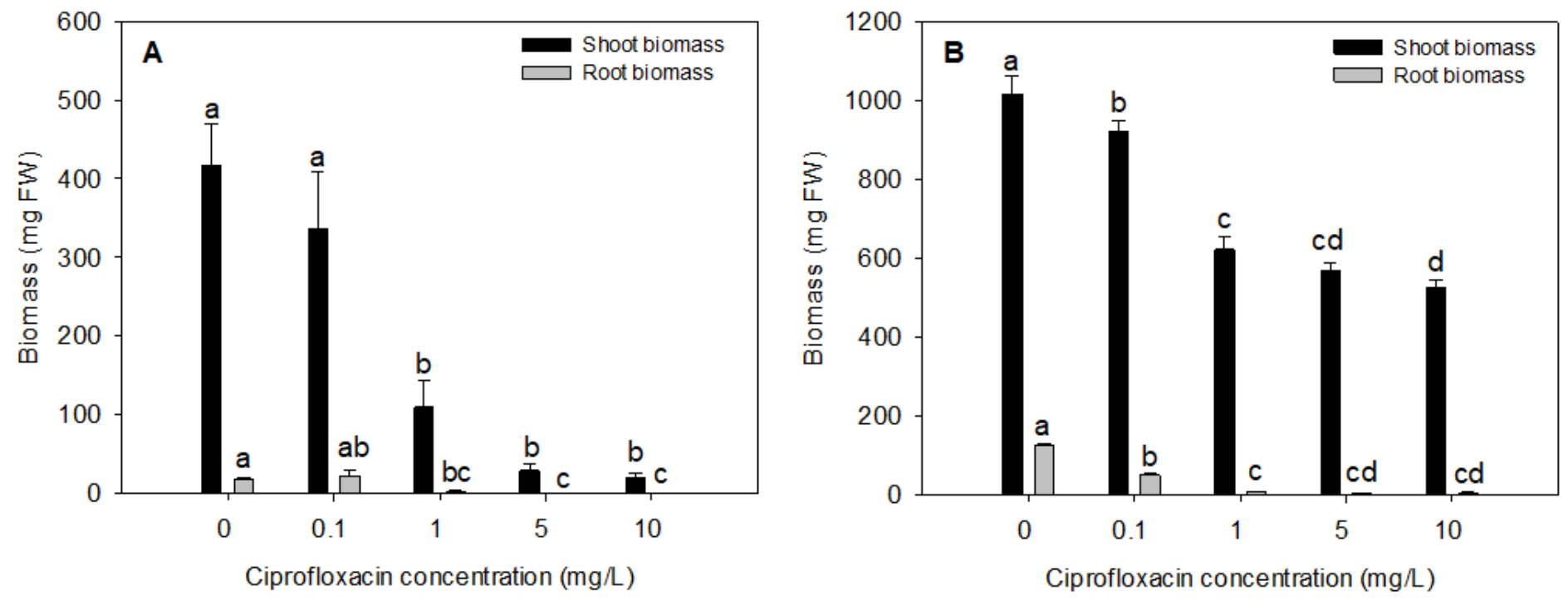

Figure 3

Biomass of $P$. crispus (A) and $H$. verticillata (B) after $35 \mathrm{~d}$ of ciprofloxacin exposure. All values represent the mean of five replicates \pm standard deviation. Different letters represent statistically significant differences among different treatments for a specific endpoint ( $p<0.05$, LSD test).
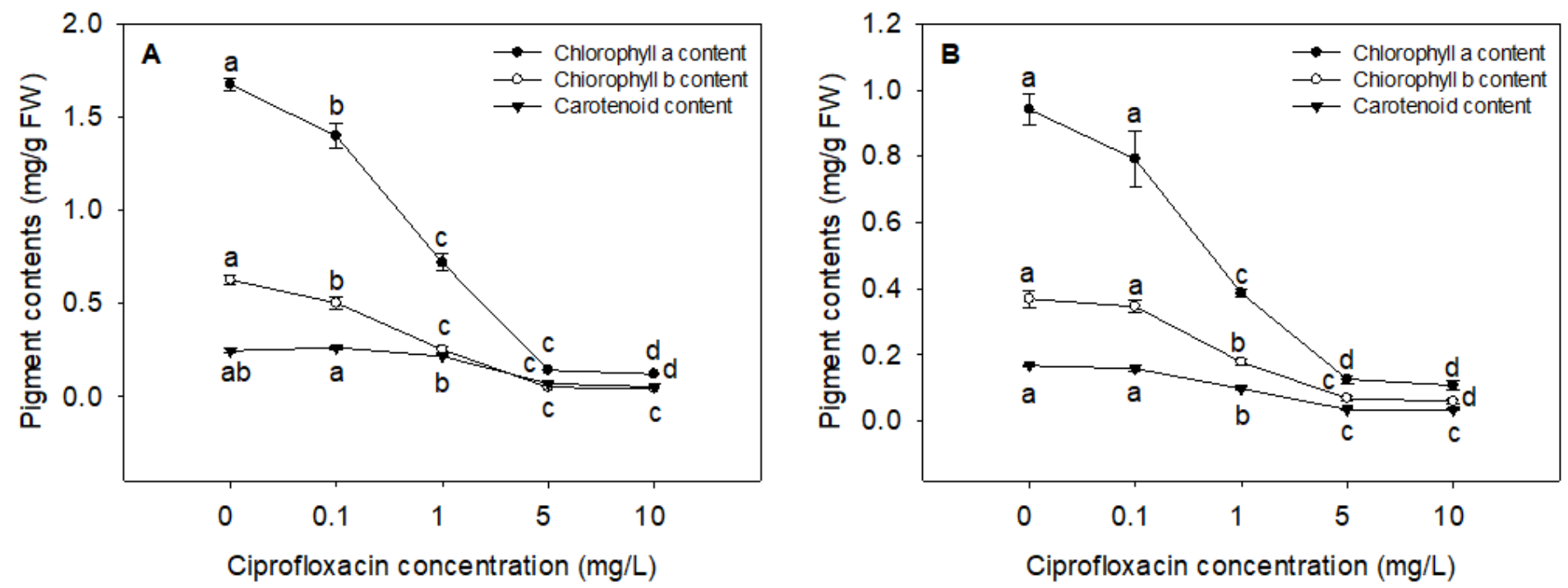

Figure 4

Pigment contents of $P$. crispus (A) and $H$. verticillata (B) after $35 \mathrm{~d}$ of ciprofloxacin exposure. All values represent the mean of five replicates \pm standard deviation. Different letters represent statistically significant differences among different treatments for a specific endpoint ( $p<0.05$, LSD test). 

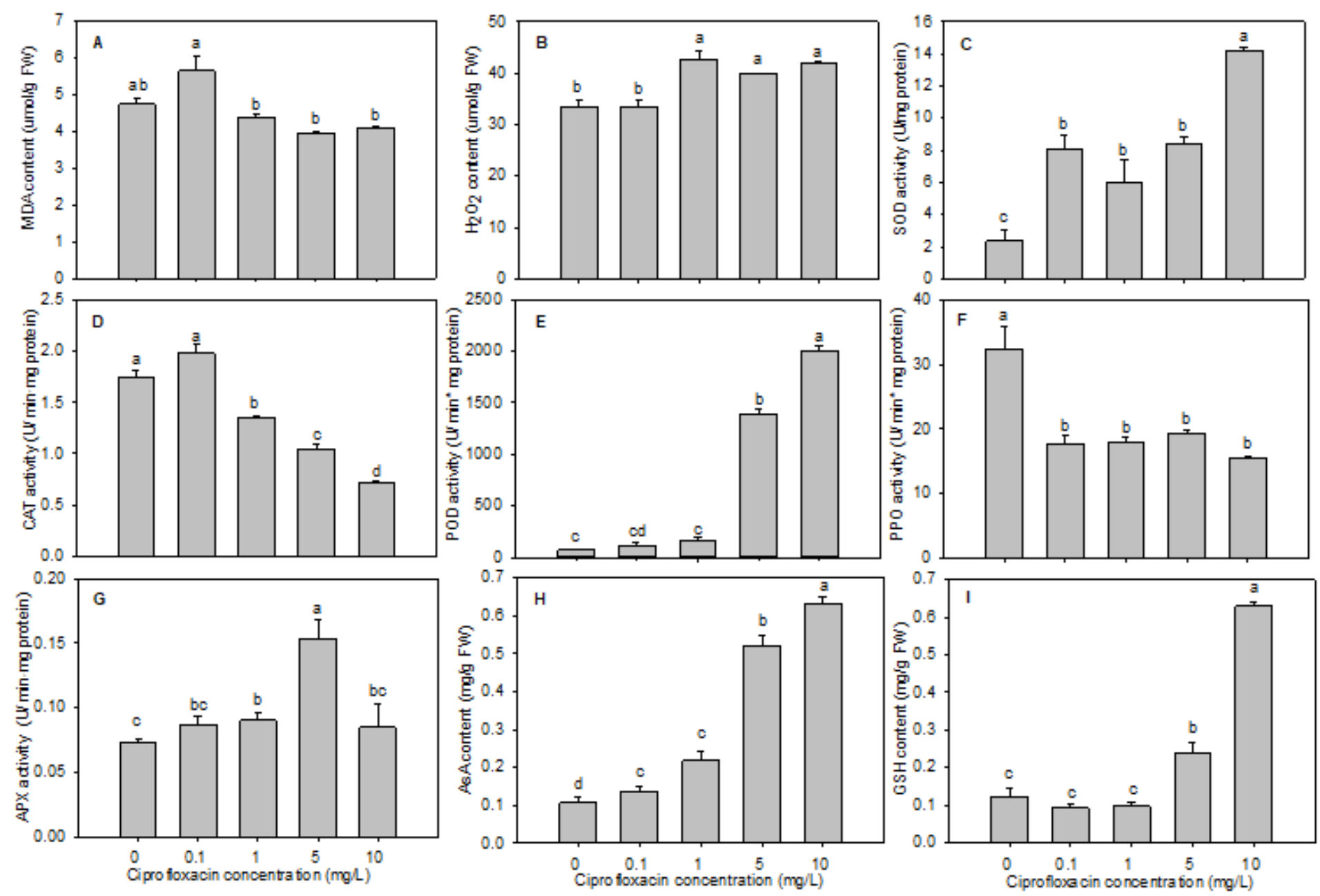

Figure 5

MDA content (A), $\mathrm{H}_{2} \mathrm{O}_{2}$ content (B), SOD (C), CAT (D), POD (E), PPO (F) and APX (G) activity, AsA content (H) and GSH content (I) of $P$. crispus exposed to ciprofloxacin. Bars represent the mean of five replicates \pm standard deviation. Different letters represent statistically significant differences among different treatments $(p<0.05$, LSD test). 

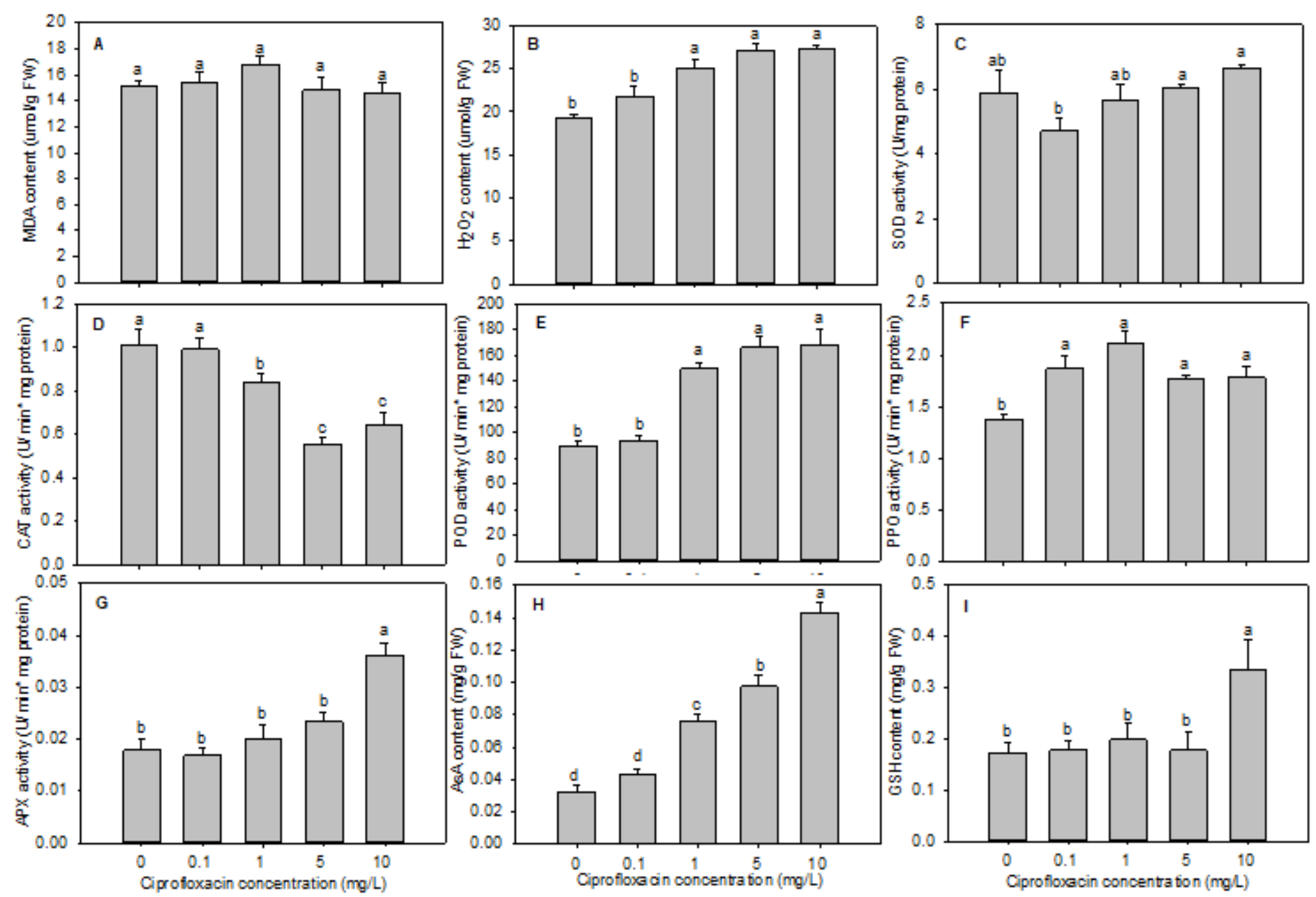

Figure 6

MDA content (A), $\mathrm{H}_{2} \mathrm{O}_{2}$ content (B), SOD (C), CAT (D), POD (E), PPO (F) and APX (G) activity, AsA content (H) and GSH content (I) of $H$. verticillata exposed to ciprofloxacin. Bars represent the mean of five replicates \pm standard deviation. Different letters represent statistically significant differences among different treatments $(p<0.05$, LSD test).

\section{Supplementary Files}

This is a list of supplementary files associated with this preprint. Click to download.

- SupplementaryInformation.docx 